\title{
Challenges in adapting technical assistive products individually for people with mobility disabilities
}

\author{
Ilona Ogurcova \\ Centre for Technical Assistance to Persons with Disability under the Ministry of Social Security and \\ Labour, Lithuania \\ E-mail: ilona.ogurcova@tpnc.lt
}

(Received 29 February 2016; accepted 27 June 2016)

Keywords: technical assistive products, individual adapting, mobility disabilities.

\section{Introduction}

Situation Analysis. The CTAPD is a budgetary institution established by the Ministry of Social Security and Labour for the purpose of organizing provision of technical assistive products to people with disability.

According to the Law on Social Integration of People with Disability and the action plan approved by the CTAPD in 2015, the CTAPD implements provision of technical assistive means to Lithuania's citizens with mobility, vision, or hearing impairments.

The CTAPD implements the following legal measures instituted by the programme "Social Integration of People with Disability" managed by the Ministry of Social Security and Labour responsible for allocated funding:

1) obtain and provide technical assistive means to persons with disability and repair said means;

2) establish conditions for activities of the Centre for Technical Assistance to Persons with Disability;

3) expand the infrastructure of the Centre for Technical Assistance to Persons with Disability.

The purpose of the CTAPD is to ensure implementation of current social integration measures, activities, and projects for people with disability intended for improvement of their medical, social, and professional rehabilitation as well as to ensure provision of technical assistive products to citizens satisfying their special needs.

Terms and Definitions:

- The main terms and definitions coincide with those used in the standard LT EN ISO 9999:2011 Assistive Products for Persons with Disability.

- TAP - technical assistive products.

- CTAPD - Centre for Technical Assistance to Persons with Disability under the Ministry of Social Security and Labour.

Programme measure - obtain and provide technical assistive means to persons with disability and repair said means.

This measure was implemented by obtaining electrical wheelchairs and mobility, vision, and hearing TAP for people with disability. Specialists of the CTAPD have chosen, adapted, and issued mobility, vision, and hearing TAP and accepted personal requests for compensation of expenses incurred in obtaining technical assistive products.

According to the approved methodology for estimation of the number of TAP necessary for people with disability, annual demand for TAP in the country was estimated at $60078 \mathrm{pcs}$. at the beginning of 2015. In 2015 CTAPD departments and municipal establishments have issued 48340 TAP (new, returned, obtained as aid), paid 1794 compensations (391 470 Eur), and provided services to 34.9 thousand of people. In 2015 the total demand for TAP was satisfied to $83.45 \%$.

Commissions established by the director of CTAPD, of which there are four, considered personal requests and made decisions in regard of adding the applicants to the queue of persons

(C) 2016 The Authors. Published by VGTU Press. This is an open-access article distributed under the terms of the Creative Commons Attribution License (CC-BY 4.0), which permits unrestricted use, distribution, and reproduction in any medium, provided the original author and source are credited. 
seeking compensation. Compensations for mobility, vision, and hearing TAP obtained by persons were paid. Certificates were issued granting persons the right to obtain TAP through enterprises and information provided on enterprise invoices and other documents submitted by individuals was checked to established whether said individual had the right to compensation of expenses incurred in obtaining a TAP through an enterprise. After studying the use of TAP obtained by individuals through enterprises, it was discovered that having bought a wheelchair for the first time the person would then have difficulties in replacing it because changes in the person's condition or inappropriate choice of the product. When buying a wheelchair for the first time a person would rely more on the options offered by a supplier then their personal opinion and would consider neither possible future medical or physical changes nor the structural peculiarities of the wheelchair. The best results were achieved when a person would obtain their first wheelchair from the CTAPD as it would then be possible to return it to the CTAPD and, having their medical and physical condition stabilized and clearly knowing their needs, the person would turn to an enterprise for a TAP with the CTAPD paying a compensation to the enterprise. People who had prior experience using wheelchairs and then chose a wheelchair through an enterprise were more satisfied with the products they obtained as they knew their own news well and had enough experience evaluating peculiarities and advantages of wheelchair designs offered by suppliers. Individual selection and adaptation of mobility TAP is very important not only for the effective use of budgetary funds but also for restoring a person's ability to function normally and aiding in the process of their integration into the society.

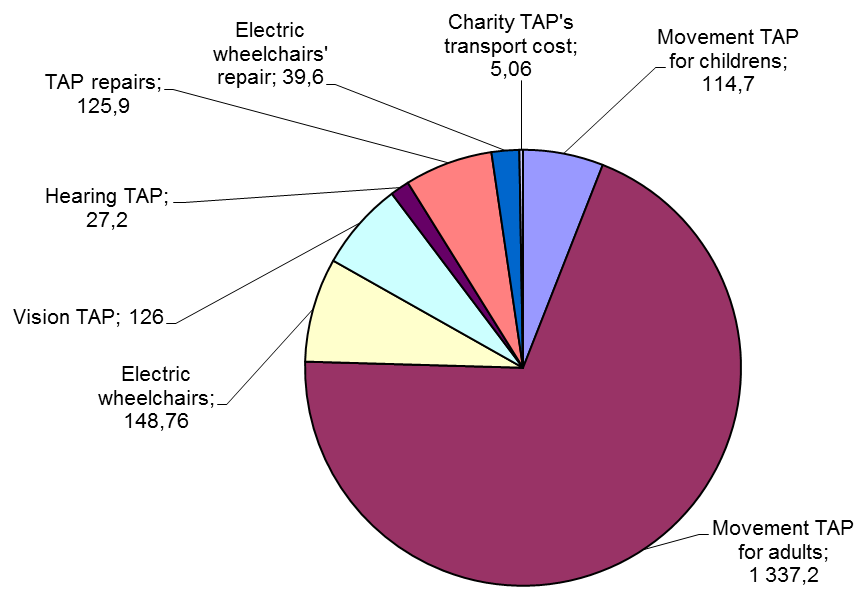

Fig. 1. Distribution of the funds used for the obtaining (exclusive of paid compensations) and repair of TAPs in 2015 (in thousands of euros)

The relevance of the situation was highlighted by the growing tension among the involved parties: the user, the TAP supplier and the Centre. It should be noted that the Centre did not find the publicly announced information about the studies of the quality of the service of selection of TAP. The Centre has established that it is not known what factors or causes may encourage the certain behaviour of the users and the TAP suppliers. Therefore, it was decided to conduct the qualitative research, the essential purpose of which is to formulate the statements and hypotheses, as well as to establish the causes of this phenomenon. It is sought to establish the essential criteria with the help of which the suitability of the selected TAP for a person could be assessed; and to form the survey algorithm for adapting TAPs individually, as the methodical instruction to the employees of CTAPD. The following methods were invoked for the conduct of this research: the in-depth and semi-structured interviews, and focus-group interviews. 


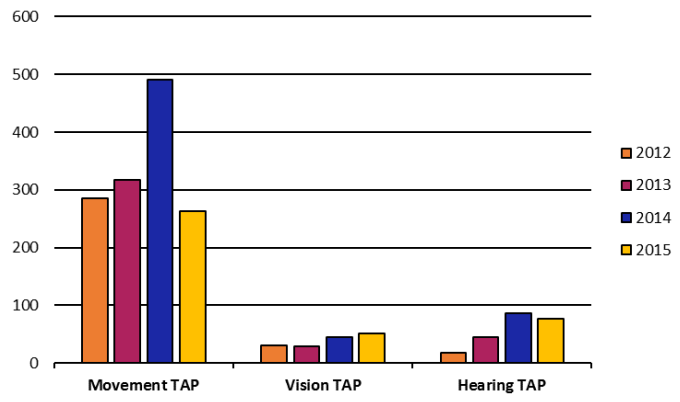

Fig. 2. Budget funds used by the Centre for the obtaining and repair of TAPs (in thousands of euros)

\section{Methodology}

During the conduct of the research, the structural peculiarities of the wheelchairs, the possibilities of interchangeability of components and assemblies, and the impact of use of additional accessories on the efficiency of operation of TAPs were researched. By applying the type of survey, such as the in-depth and semi-structured interviews, it was sought to obtain the non-structured information about the issue being researched as much as possible. The process and style of the interviews depended on the goals set by the researcher for himself; however, in all cases, the researcher and the surveyor interacted. Such method provided the possibility to find out the intensity of this topic, and the representation of the issues, in the selected data source. The focus-group interviews were also held in this manner - it is one of the qualitative methods of data selection used mostly in the world. During this research, a conversation with a small group of respondents was held on a foreseen topic of conversation. On 25/9/2015, in the Landscape Therapy and Recreation Centre, CTAPD, along with the social partners involved in the research, seeking to establish the universal technological structure of the basic model of the active type of the wheelchairs, which could be adapted individually for each user, by using the various accessories and/or other additional/alternative parts offered by the manufacturer, organized and performed the research and practice seminar. During this seminar, the focus-group interviews distinguished themselves by the synergic effect which enabled a variety of opinions, ideas, and experiences. The research on the focus-group interviews was useful; while looking for the new information (e.g. the opinion about TAPs and their usage), it was sought to hear different opinions on the same topic, by illustrating them with the words of the very Respondents; it is desired to learn why the Participants behave one way or another, what their motives and attitudes are; it is sought to reveal the ways by which the individuals affect each other; and it was to obtain more various information in a greater number.

\section{Respondents}

The research involved the members of the Paraplegic Associations of the Republic of Lithuania, who tested TAPs that were provided to them, and gave feedback; as well as the Suppliers of the Centre who, in accordance with the valid procedure of providing the persons with TAPs, supply various wheelchairs (of different manufacturers, types and models), the kinesiotherapists and the rehabilitologists of the Health Care Institutions. The research involved total 20 persons who were using the wheelchair. The participants were divided into 3 groups. All groups discussed on the indicated topic: "Possibilities of adjustment of the wheelchair and their importance to the correct seat posture: possibilities of adjustment of the seat width and foot support; adjustment of the height and tensioning of the back support; and possibilities of adjustment of the height of hand supports." During the first task, the members of each group had, by mutual agreement, to express in one word what, in their opinion, is most necessary for the user of the wheelchair from the specialists of the Centre. The topics of open discussions were named 
in these words, which formed the contents of the second task. During the second task, the respondents took part in the open discussions which were held by the moderators appointed by the organizer, who asked the prepared open questions. The wheelchairs of different manufacturers and the possibilities of their adjustment were demonstrated during discussions. TAPs of the following companies were examined: Meyra, Ottobock, Vermeiren, Offcarr, Kuschell, Panthera.

\section{Results}

Essential conclusions and suggestions are given in the table 1. The necessary requirements for TAPs for the better integration of the person in the society were specified.

Table 1. Essential conclusions and suggestions

\begin{tabular}{|c|c|c|c|}
\hline \multirow{2}{*}{$\begin{array}{l}\text { Section } \\
\text { No. }\end{array}$} & \multicolumn{3}{|c|}{ Group name and specified requirements for TAPs } \\
\hline & TOLERANCE & RESPECT & TRUST \\
\hline Section I & $\begin{array}{l}\text { - Flexible wheel protections } \\
\text { - Fork frame folding } \\
\text { mechanism } \\
\text { - Good cohesion of arcs with } \\
\text { the palm }\end{array}$ & $\begin{array}{l}\text { - We know how to sit } \\
\text { correctly, but we sit } \\
\text { conveniently } \\
\text { - The correct seat posture } \\
\text { from the very beginning } \\
\text { - The tensioning of the } \\
\text { backrest for the stable seat } \\
\text { posture } \\
\text { The footrests create the } \\
\text { load for the joints }\end{array}$ & $\begin{array}{l}\text { The very user shall } \\
\text { like it. }\end{array}$ \\
\hline Section II & $\begin{array}{l}\text { The weight of TAP is the } \\
\text { very significant criterion } \\
\text { for transportation } \\
\text { - The check of technical } \\
\text { condition every } 12 \text { months } \\
\text { during the warranty period } \\
\text { - The adjustment of the } \\
\text { height of the backrest by } \\
\text { passing to the more active } \\
\text { usage }\end{array}$ & $\begin{array}{l}\text { The tilt of the seat is adjusted } \\
\text { by } 3 \text { belts }\end{array}$ & $\begin{array}{l}\text { - The lighter ones are } \\
\text { less adjusted, but the } \\
\text { more experienced } \\
\text { users shall use them } \\
\text { - For the beginners, } \\
\text { max. adjustment, } \\
\text { from } 1 \text { to } 6 \text { months }\end{array}$ \\
\hline Section III & $\begin{array}{l}\text { - Adjustment of the footrest } \\
\text { angle, stiffening of the } \\
\text { backrest from } 46 \mathrm{~cm} \\
\text { - Tensioning of the seat is } \\
\text { adjusted not only by the } \\
\text { stripes }\end{array}$ & $\begin{array}{l}\text { - Covered front wheel caster } \\
\text { bearings } \\
\text { - Fork frame mechanism } \\
\text { - Front caster fork angle } \\
\text { - Total height is adjusted by } \\
\text { the wheel beam } \\
\text { - Adjustable armrests }\end{array}$ & $\begin{array}{l}\text { I've seen it and I like } \\
\text { it, and the rest may be } \\
\text { tamed }\end{array}$ \\
\hline
\end{tabular}

\section{Conclusions and suggestions}

It has been concluded that the essential criterion for evaluation of effective TAP use is personal energy commitment. This is to say that a person using different products of the same type to perform the same kind of action commits a different amount of energy because of product design peculiarities and choice of accessories. In other words, several TAP are offered to a person after assessing their everyday needs and impairments. The TAP that is the most suitable for the person is the one using which they commit the least amount of energy.

Currently, the CTAPD and DWCAO (Disability and Working Capacity Assessment Office), using the International Statistical Classification of Diseases and Related Health Problems (ICD) and International Classification of Functioning, Disability and Health (ICF), are working on functional ability identification tests that could be used to determine energy commitments when using this or that TAP. 